\title{
The Effect of Transformer Leakage Inductance on the Steady State Performance of Push-pull based Converter with Continuous Current
}

\author{
Qian Chen ${ }^{\dagger}$, Trillion Q. Zheng ${ }^{\star}$, Yan $\mathrm{Li}^{\star}$, and Tiancong Shao* \\ ${ }^{\dagger \star}$ School of Electrical and Engineering, Beijing Jiaotong University, Beijing, China
}

\begin{abstract}
As a result of the advantages such as high efficiency, continuous current and high stability margin, push-pull converter with continuous current (PPCWCC) is competitive for battery discharge regulator (BDR) which plays an important role in power conditioning unit (PCU).Leakage inductance yields current spike in low-ripple current of PPCWCCs. The operating modes are added due to leakage inductance. Therefore the steady state performance is affected, which is embodied in the spike of low-ripple current. PPCWCCs which are suitable for BDR can be separated into three types by current spike characteristics. Three representative topologies IIs1, IIcb2 and Is3 are analyzed in order to investigate the factors on the magnitude and duration of spike. Equivalent current sampling method (ECSM) which eliminates the sampling time delay and achieves excellent dynamic performance is adopted to prevent the spike disturbance on current sampling. However, ECSM reduces the sampling accuracy and telemetry accuracy due to neglecting the spike. In this paper, ECSM used in PPCWCCs is summarized. The current sampling error is analyzed in quality and quantity, which provides the foundation for offsetting and enhancing the telemetry accuracy. Finally, current sampling error rate of three topologies is compared by experiment results, which verify the theoretical analysis.
\end{abstract}

Key words: Current sampling error, Current spike, Equivalent current sampling, Leakage inductance, Push-pull converter

\section{INTRODUCTION}

Satellite power supply system which is an important element of satellite is a system that generates, stores, transforms and distributes electricity. As the core of Satellite power supply system, primary electrical power system powers the equipments in satellite and protects power supply system. A joint-power-supply consists of solar array and lithium-ion battery is adopted due to the merits of high reliability, long serving life and light weight [1]-[9]. Power conditioning unit (PCU) which is mainly composed of battery discharge regulator (BDR), battery charge regulator (BCR) and solar array regulator (SAR) is a typical primary electrical power system. The architecture of PCU is shown as Fig.1. Compared with the multisource power generation system in [10] and [11], the charge current of the PCU shown in Fig.1 can be controlled precisely, which is beneficial to prolong the battery life.

Manuscript received Nov. 7, 2012; revised Feb. 22, 2013

Recommended for publication by Associate Editor Honnyong Cha.

${ }^{\dagger}$ Corresponding Author: chenqian05291148@126.com

Tel: +86-10-51684911-20, Fax: +86-10-51684029, Beijing Jiaotong Univ.

${ }^{*}$ School of Electrical and Engineering, Beijing Jiaotong University, China

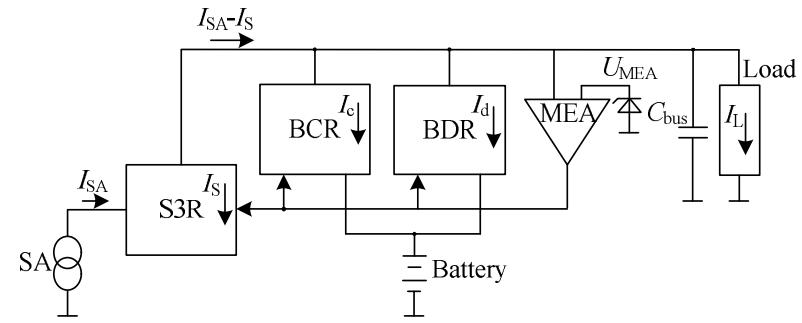

Fig. 1. Diagram of PCU.

When satellites can't get enough energy from solar array in shadow region or sunshine region, BDR regulates the power that flows from battery to load. PPCWCC is widely adopted as BDR on account of high efficiency, continuous current and convenience to parallel.

Input and output current of PPCWCC are both above zero at any time. If the turn ratio of transformer and coupled inductor are designed properly, input or output current of PPCWCC will be low-ripple which means the average current during switch-on state is equal to that during switch-off state. PCU is a three-domain control system, which is controlled by the bus current of BCR, BDR and S3R 
to regulate the bus voltage. It's more convenient to sample if the bus current is low-ripple [12]. Therefore, PPCWCC whose output current is low-ripple is suitable for BDR.

At present, Weinberg converter which is belong to PPCWCCs has been already adopted as BDR in several PCUs with different models [13]-[16]. Although output current of Weinberg converter is low-ripple, the spike exists in output current. Reference [17] and [18] analyze the current spike of Weinberg converter briefly. However, the current spike hasn't been analyzed in detail, such as the magnitude and average value of current spike. The impact of current spike is also not mentioned. Actually, for PPCWCCs which are suitable for BDR, current spike always exists in output current, which is induced by leakage inductance. The current sampling accuracy and telemetry accuracy are impacted by current spike. Thus it's essential to pay attention on current spike of PPCWCC.

A series of PPCWCCs are proposed in [19], [20]. This paper focuses on PPCWCCs whose output current is low-ripple. They are classified into three types based on different characteristics of current spike. Three topologies which represent three spike characteristics are analyzed in quality and quantity to investigate the main factors that influence the magnitude and duration of current spike. The error that is introduced by equivalent current sampling method (ECSM) is also analyzed and compared.

This paper is organized as follows. Section II proposes the concept of PPCWCC and divides them into three types. Section III analyzes the current spike of topology IIs1, IIcb2 and Is 3 in quality and quantity. Section IV summarizes the factors on current spike. To overcome the disturbance of current spike, section V introduces ECSM, while section VI analyzes the problem induced by ECSM. Finally the experimental results and conclusions are given in section VII and VIII.

\section{ClassificAtion Of SPIKE CHARACTERISTICS}

As is shown in Fig. 2, four kinds of push-pull cells which are the core of PPCWCC are named as I, II, III and IV.

Compared with traditional push-pull cell, push-pull cell I, shown as Fig. 2(a), connects the centre tap of secondary winding with positive terminal of power supply, which boosts voltage with continuous input and output current. For push-pull cell I, MOSFET is connected with the primary winding. When $Q_{1}$ is switched on, the potential of transformer which is negative in homonymous-ends makes the diode $D_{1}$ switch on; When $Q_{2}$ is switched on, the potential of transformer which is positive in homonymous-ends makes the diode $D_{2}$ switch on.

Traditional push-pull cell is equivalent as a pair of forward cells in parallel. For push-pull cell I, current only flows through two of the four transformer windings when $Q_{1}$ or $Q_{2}$

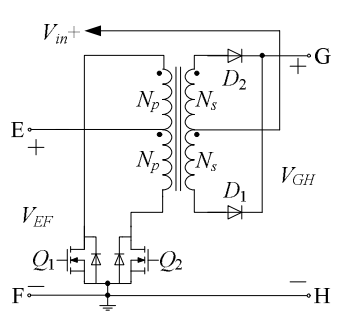

(a)

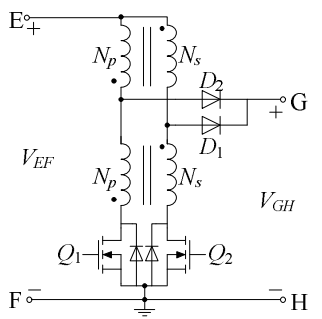

(c)

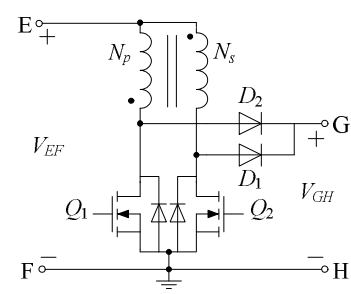

(b)

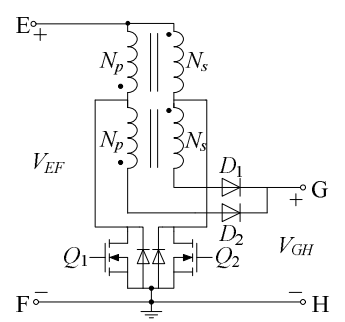

(d)
Fig. 2. Four new push-pull cells (a) push-pull cell I (b) push-pull cell II (c) push-pull cell III (d) push-pull cell IV.

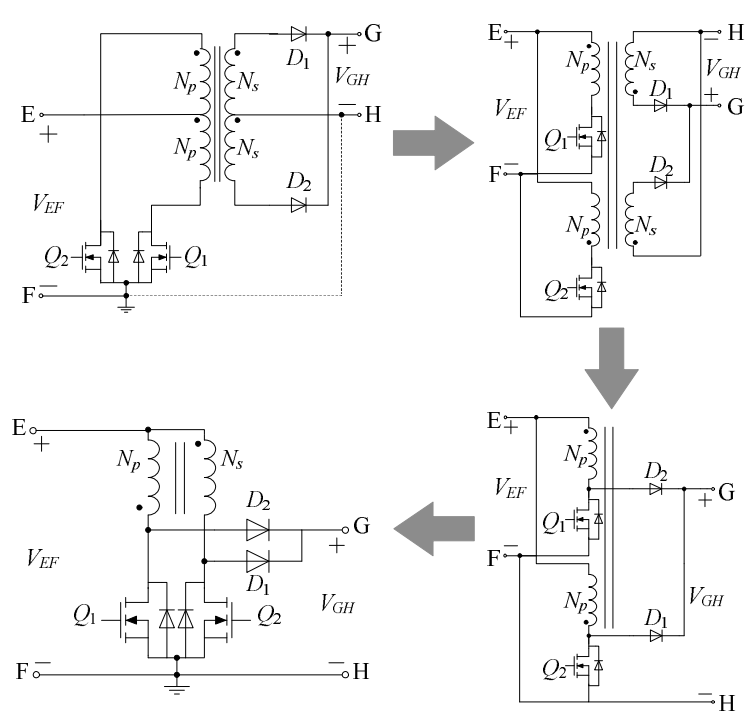

Fig. 3. Derivation of II type push-pull cell.

is switched on. In order to reduce transformer volume, push-pull cell II is derived by connecting the anode of $D_{1}$ and $D_{2}$ with the drain of $Q_{1}$ and $Q_{2}$, which is shown in Fig. 3. Meanwhile, current flows through both of the transformer windings when $Q_{1}$ or $Q_{2}$ is switched on.

Push-pull cell III and IV, shown as Fig. 2(c) and Fig.2(d), are derived from push-pull cell II by substituting the four-winding transformer for two-winding transformer to achieve different voltage gain ${ }^{[21]}$. Unlike push-pull cell I, MOSFETs are connected with primary and secondary windings seperately for push-pull cell II, III, IV. It should be pointed out that the primary and secondary windings are not fixed and the winding which is connected with the switched-on MOSFET is the primary winding. 


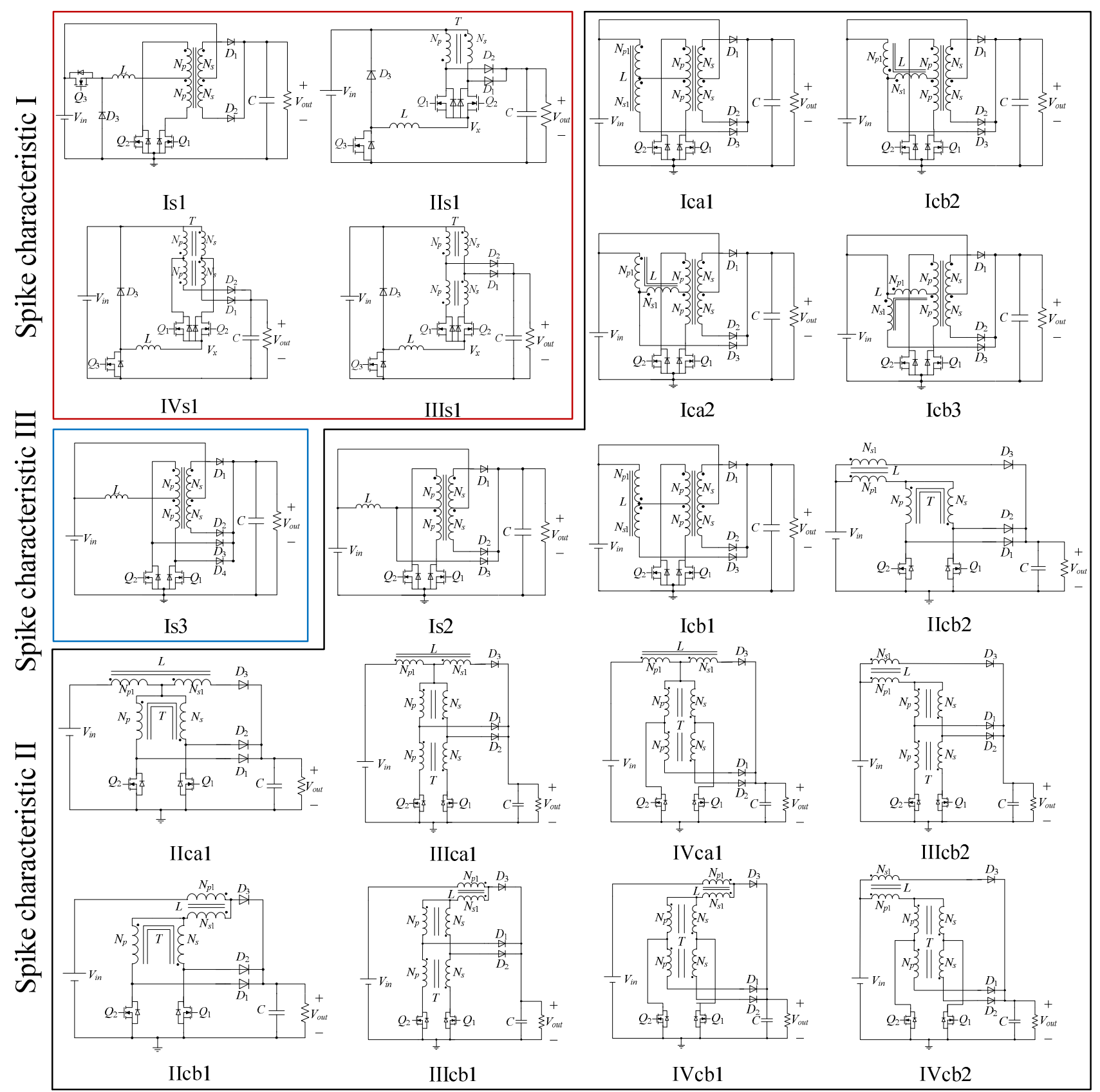

Fig.4. Push-pull based converter with continuous current.

Fig. 4 shows twenty PPCWCCs for BDR which are generated from four kinds of push-pull cells. These topologies are named as the following rules: The first bit means the push-pull cell, four kinds of push-pull cells are named as I, II, III, IV respectively. The second bit expresses the inductor structure, single inductor is named as 's' while coupled inductor is named as ' $c$ '. The third bit means rank for the topology with single inductor or the connecting way of inductor for the topology with coupled inductor, positive connection is named as ' $a$ ' while negative connection is named as ' $b$ '. The fourth bit expresses rank for the topology with coupled inductor. These topologies can be divided into three types according to different spike characteristics:

Spike characteristic I: negative spike exists in low-ripple current. Topologies with this spike characteristic includes Is1, IIs1, IIIs1 and IVs1.

Spike characteristic II: positive spike exists in low-ripple current. Topologies with this spike characteristic includes Ica1, IIca1, IIIca1, IVca1, IIcb1, IIIcb1, IVcb1, Icb3, IIcb2, IIIcb2, IVcb2, Is2, Ica2, Icb1 and Icb2.

Spike characteristic III: both of negative and positive spikes exist in low-ripple current simultaneously. Topology with this spike characteristic includes Is3. 


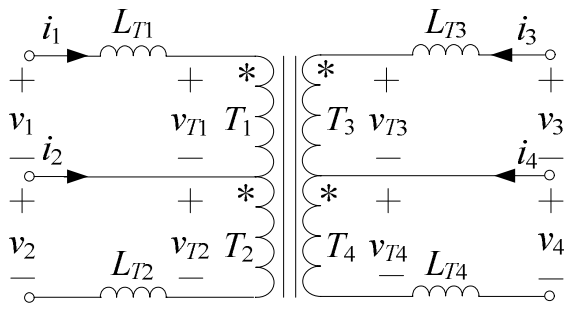

Fig. 5. Positive direction of voltage and current for transformer.

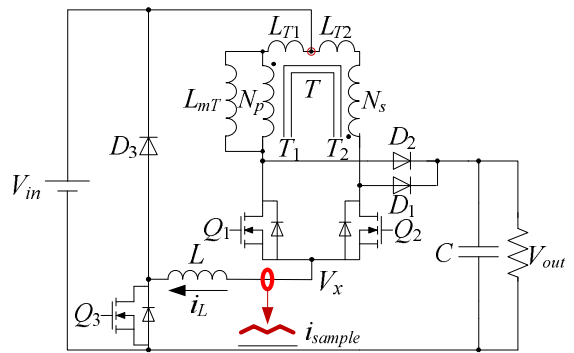

Fig. 6. Topology IIs1 with magnetizing inductance and leakage inductance.

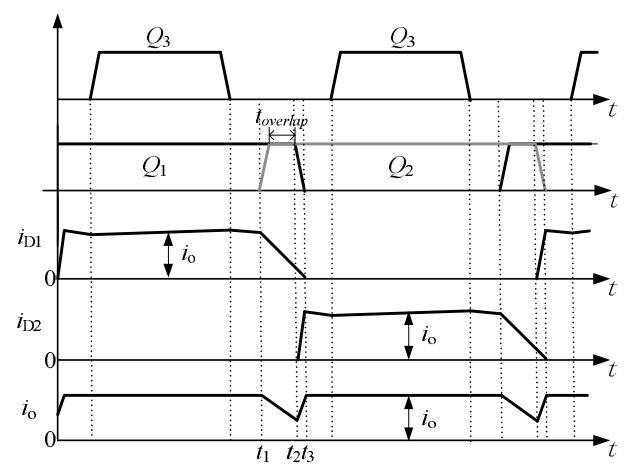

Fig. 7. Current waveform of topology IIs1.

\section{ANALYSIS OF CURRENT SPIKE FOR THREE TOPOLOGIES}

Topology IIs1, IIcb2 and Is3 which are on behalf of three spike characteristics are chosen to analyze. The positive direction of voltage and current for transformer, shown as Fig.5, are defined as follows: the electric potential of homonymous-ends and the current flowing into homonymous-ends is positive. Due to the single turn ratio, $L_{\mathrm{T} 1}=L_{\mathrm{T} 2}=L_{\mathrm{T} 3}=L_{\mathrm{T} 4}=L_{\mathrm{T}}, v_{\mathrm{T} 1}=v_{\mathrm{T} 2}=v_{\mathrm{T} 3}=v_{\mathrm{T} 4}=v_{\mathrm{T}}$ are satisfied. If the magnetic resistance can be neglected

$$
N_{1} i_{1}+N_{2} i_{2}+N_{3} i_{3}+N_{4} i_{4}=0
$$

\section{A. Topology IIs 1}

Topology IIs1, shown in Fig.6, is a current fed push-pull based converter. In order to keep the current of inductor flowing regularly, the duty cycle of $Q_{1}$ and $Q_{2}$ should be a bit higher than 0.5 and the phase difference is 180 degrees. When $Q_{1}$ and $Q_{2}$ are switched on simultaneously, the output current will reduce dramatically to induce a negative spike. From the current waveform of topology IIs1 in Fig.7, the negative spike transition is separated into two stages $\left(t_{1} \sim t_{2}\right.$ stage and $t_{2} \sim t_{3}$ stage) to analyze.

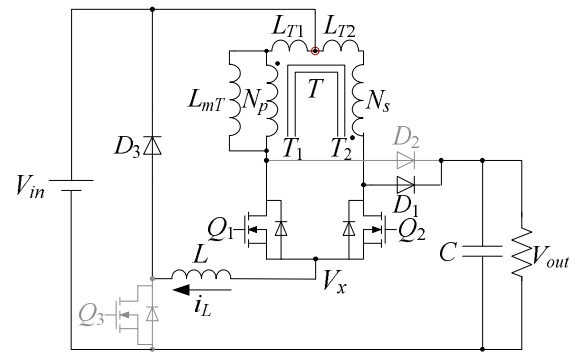

(a)

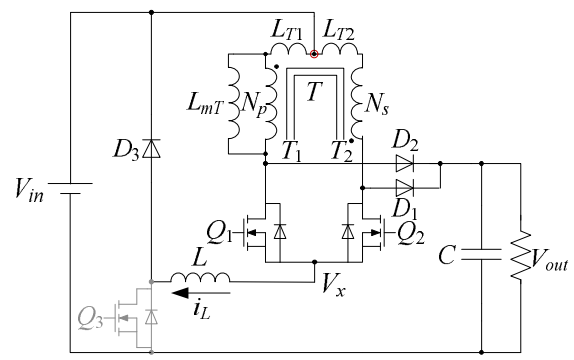

(b)

Fig. 8. Equivalent circuit of topology IIs1 during (a) $t_{1} \sim t_{2}$ stage (b) $t_{2} \sim t_{3}$ stage.

According to Eq.(1), the primary current and secondary current satisfy

$$
i_{Q 2}+i_{D 1}=i_{Q 1}+i_{D 2}
$$

The current of inductor $L$ is equal to the sum of the current that is flowing through $Q_{1}$ and $Q_{2}$.

$$
i_{Q 1}+i_{Q 2}=i_{L}
$$

The equivalent circuit during $t_{1} \sim t_{2}$ stage is shown in Fig.8 (a). Current flows through $Q_{1}$ and $Q_{2}$ simultaneously, therefore the current flowing through $D_{1}$ starts to reduce from $t_{1}$ to $t_{2}$.

Fig. 8 (b) shows the equivalent circuit during $t_{2} \sim t_{3}$ stage. Current flows through $Q_{1}, Q_{2}, D_{1}$ and $D_{2}$ simultaneously. At $t_{3}, i_{\mathrm{D} 1}$ reduces to zero and $i_{\mathrm{D} 2}$ reach the steady state.

Considering magnetizing inductance and leakage inductance, the winding voltage of transformer is expressed as

$$
\left\{\begin{array}{c}
v_{1}=v_{L T 1}+v_{T 1}=v_{\text {out }}-v_{\text {in }} \\
v_{2}=v_{T 2}-v_{L T 2}=v_{\text {in }}-v_{\text {out }}
\end{array}\right.
$$

Equation (4) is simplified as

$$
-0.5 L_{T} \frac{d i_{Q 1}}{d t}-0.5 L_{T} \frac{d i_{Q 2}}{d t}-0.5 L_{T} \frac{d i_{D 1}}{d t}=v_{\text {out }}-v_{\text {in }}
$$

During $t_{1} \sim t_{2}$ stage, the current flowing through $D_{2}$ is zero. By differentiating Eq.(2) and (3)

$$
\frac{d i_{D 1}}{d t}=2 \frac{d i_{Q 1}}{d t}=-2 \frac{d i_{Q 2}}{d t}
$$

Substituting Eq.(6) into Eq.(5) yields

$$
L_{T} \frac{d i_{D 1}}{d t}=-2\left(v_{\text {out }}-v_{\text {in }}\right)
$$

The variation of $i_{D 1}$ is $i_{o}$ during $t_{1} \sim t_{3}$ stage, so the duration 


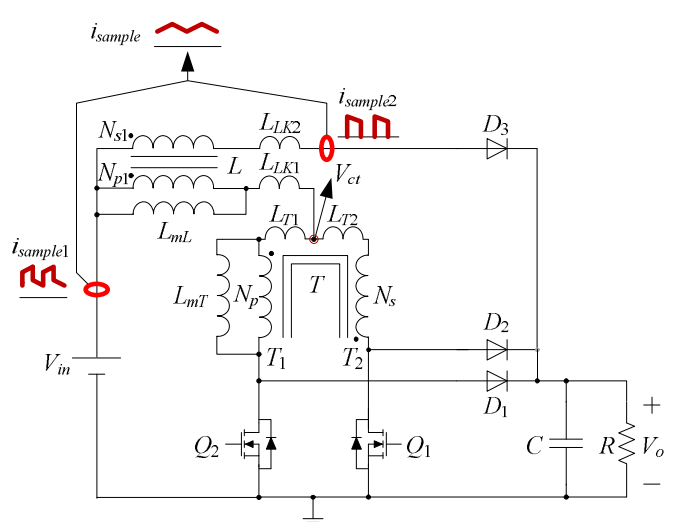

Fig. 9. Topology IIcb2 with magnetizing inductance and leakage inductance.

of negative spike is

$$
t_{n-\text { spike }}=t_{3}-t_{1}=\frac{L_{T} i_{o}}{2\left(v_{\text {out }}-v_{\text {in }}\right)}=t_{\text {off }- \text { on }}+t_{\text {on-off }}+t_{\text {overlap }} \text { (8) }
$$

The output current reduces to the minimum at $t_{2}$. Thus the negative spike is

$$
i_{n-\text { spike }}=i_{D 1}+i_{D 2}=i_{D 1}\left(t_{2}\right)=i_{o}-2 \frac{v_{\text {out }}-v_{\text {in }}}{L_{T}}\left(t_{2}-t_{1}\right)
$$

In Eq.(9), $t_{2}-t_{1}$ is added by the rise time of MOSFET $t_{\text {off-on }}$ and overlap conduction time $t_{\text {overlap. }}$.

Using Eq.(8) in Eq.(9) yields

$$
\begin{aligned}
& i_{n-\text { spike }}=i_{D 1}+i_{D 2}=i_{D 1}\left(t_{2}\right) \\
& =i_{o}-2 \frac{v_{\text {out }}-v_{\text {in }}}{L_{T}}\left(\frac{L_{T} i_{o}}{2\left(v_{\text {out }}-v_{\text {in }}\right)}-t_{\text {on-off }}\right)
\end{aligned}
$$

\section{B. Topology IIcb2}

Considering the magnetizing inductance and leakage inductance, topology IIcb2 is shown in Fig.9. The magnetizing inductance and leakage inductance of coupled inductor is given in Eq.(11).

$$
\left\{\begin{array}{c}
L_{L K 1}=\frac{N_{1} \Phi_{11}\left(1-k_{1}\right)}{i_{1}}=L_{1}\left(1-k_{1}\right) \\
L_{L K 2}=\frac{N_{2} \Phi_{22}\left(1-k_{2}\right)}{i_{2}}=L_{2}\left(1-k_{2}\right)
\end{array}\right.
$$

$L_{1}$ and $L_{2}$ are the self inductance of primary and secondary winding respectively. The closer the coupling coefficient $\sqrt{k_{1} \cdot k_{2}}$ is to single, the smaller the leakage of coupled inductor $L_{L K}$ will be. Suppose that the turn ratio of coupled inductor and transformer is $N_{1}=N_{p 1} / N_{s 1}$ and $N_{2}=N_{p} / N_{s}$ separately, $N_{2}=2 N_{1}=1$ should be satisfied to realize low-ripple output current.

Fig. 10 shows the current waveform of topology IIcb2. The positive spike exists during the transition that MOSFET is switched off. The positive spike transition is separated into two stages $\left(t_{1} \sim t_{2}\right.$ stage and $t_{2} \sim t_{3}$ stage) to analyze.

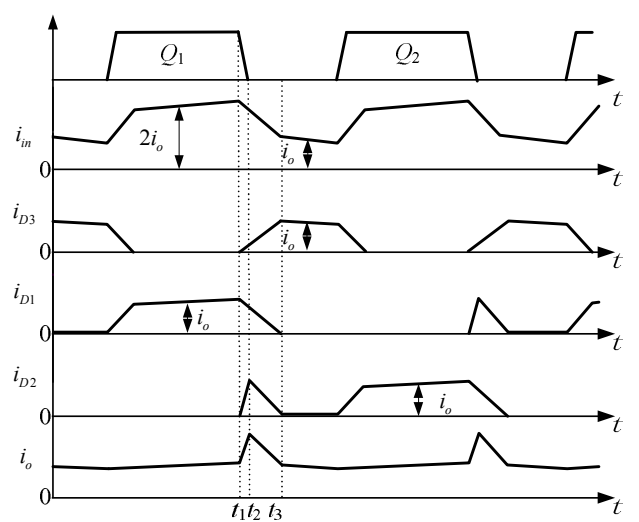

Fig. 10. Current waveform of topology IIcb2.

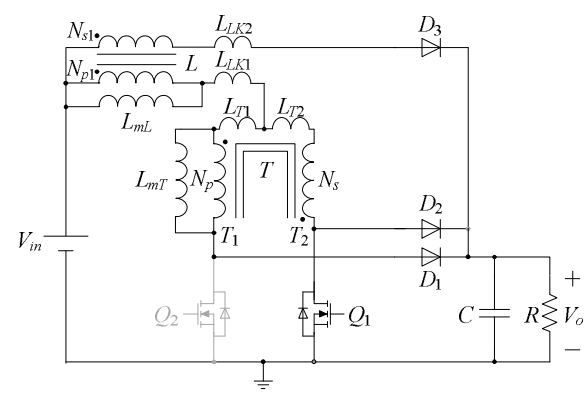

(a)

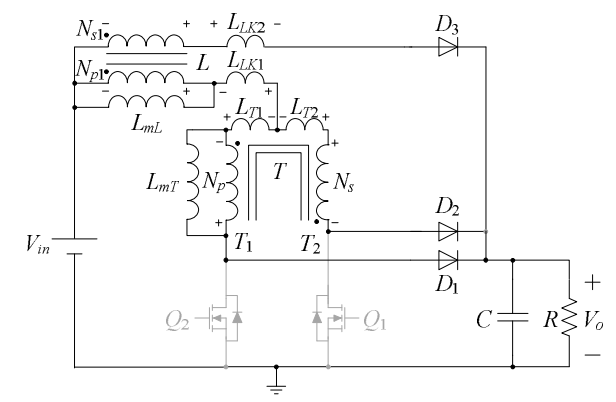

(b)

Fig. 11. Equivalent circuit of topology IIcb2 during (a) $t_{1} \sim t_{2}$ stage (b) $t_{2} \sim t_{3}$ stage.

Based on Eq.(1)

$$
i_{Q 2}+i_{D 1}=i_{Q 1}+i_{D 2}
$$

For topology IIcb2, the sum of input current and diode current $i_{\mathrm{D} 3}$ is twice of output current, therefore

$$
2 i_{D 3}+i_{D 1}+i_{D 2}+i_{Q 1}+i_{Q 2}=2 i_{o}
$$

The equivalent circuit during $t_{1} \sim t_{2}$ stage is shown in Fig.11(a). As $Q_{1}$ is switched off, the current flowing through $Q_{1}$ and $D_{1}$ reduce from $i_{o}$ and the current flowing through $D_{3}$ and $D_{2}$ rise from 0 . At $t_{2}$, the output current is at its maximum.

Fig.11(b) shows the equivalent circuit of $t_{2} \sim t_{3}$ stage. During this stage, $i_{D 3}, i_{D 1}$ and $i_{D 2}$ reach stable states at $t_{3}$. Meanwhile, $D_{1}$ and $D_{2}$ are already switched off and the current of diode $D_{3}$ is $i_{o}$.

The leakage inductance voltage of transformer is 


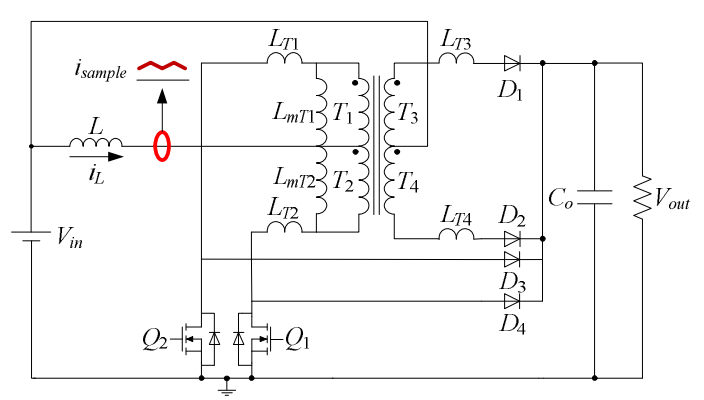

Fig. 12. Topology Is 3 with magnetizing inductance and leakage inductance.

$$
v_{L T 1}=v_{L T 2}=v_{L T}=-L_{T} \frac{d i_{D 1}}{d t}
$$

The turn ratio of coupled inductor is 0.5 , therefore the secondary leakage inductance is quadruple of the primary leakage inductance, that is $L_{L K 2}=4 L_{L K 1}=4 L_{L K}$. The leakage inductance voltage of coupled inductor is

$$
v_{L K 2}=2 v_{L K 1}=2 v_{L K}=-2 L_{L K 1} \frac{d\left(i_{D 1}+i_{D 2}\right)}{d t}
$$

Equation (16) is derived by compiling the voltage loop equation.

$$
v_{i n}+v_{N_{p 1}}+v_{L K 1}+v_{L T 1}+v_{N_{p}}=v_{\text {out }}
$$

Substitute Eq.(14) and (15) to (16) yields

$$
-4 L_{L K} \frac{d i_{D 1}}{d t}-4 L_{L K} \frac{d i_{D 2}}{d t}-2 L_{T} \frac{d i_{D 1}}{d t}=v_{\text {out }}-v_{\text {in }}
$$

During $t_{2} \sim t_{3}$ stage, the current of $Q_{1}$ and $Q_{2}$ is equal to zero. According to Eq.(12) and (13)

$$
\frac{d i_{D 1}}{d t}=\frac{d i_{D 2}}{d t}=-\frac{d i_{D 3}}{d t}
$$

Comparing Eq.(18) and Eq.(17) yields

$$
\left(8 L_{L K}+2 L_{T}\right) \frac{d i_{D 3}}{d t}=v_{\text {out }}-v_{\text {in }}
$$

During $t_{1} \sim t_{3}$ stage, the variation of $i_{D 3}$ is $i_{o}$, so the duration of positive spike is

$$
t_{p-\text { spike }}=t_{3}-t_{1}=\frac{i_{o}\left(8 L_{L K}+2 L_{T}\right)}{v_{\text {out }}-v_{\text {in }}}
$$

The positive spike is

$$
\begin{aligned}
& i_{p-\text { spike }}=i_{D 1}+i_{D 2}+i_{D 3}=2 i_{o}-i_{D 3}\left(t_{2}\right) \\
& =2 i_{o}-\frac{v_{\text {out }}-v_{\text {in }}}{8 L_{L K}+2 L_{T}}\left(t_{2}-t_{1}\right)
\end{aligned}
$$

In Eq.(21), $t_{2}-t_{1}$ is equal to the fall time of MOSFET $t_{\text {on-off }}$

\section{Topology Is 3}

Fig.12 shows topology Is 3 with magnetizing inductance and leakage inductance. When the turn ratio of transformer is single, the output current is low-ripple. The positive spike exists during switch-off transition while the negative spike exists during switch-on transition, which is shown in Fig. 13.

According to Eq.(1)

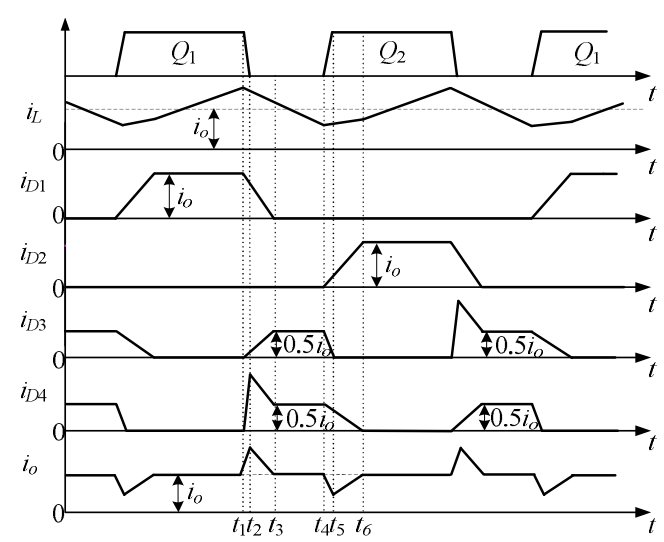

Fig. 13. Current waveform of topology Is3.

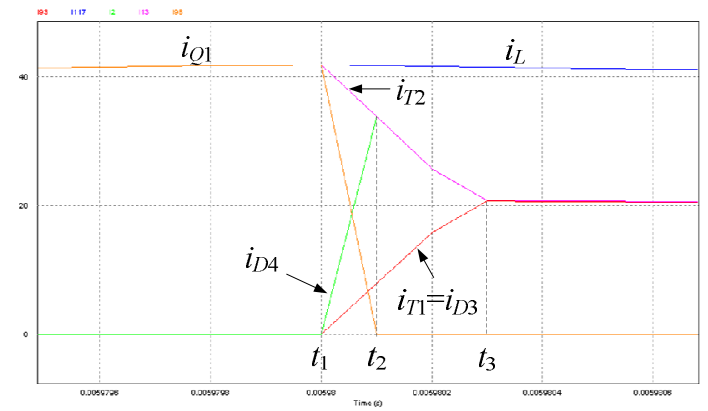

(a)

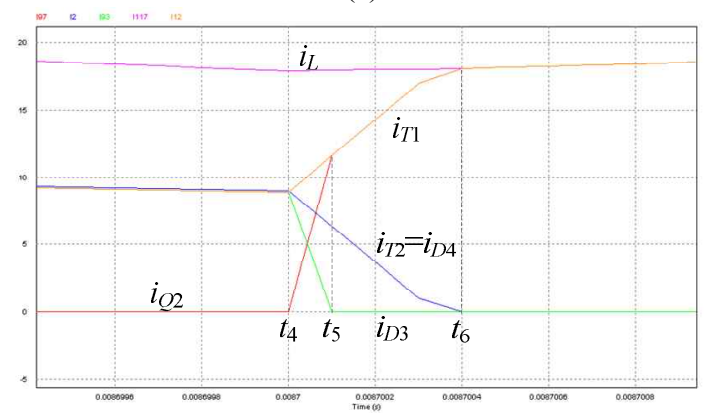

(b)

Fig. 14. Current waveform of topology Is3 during (a) switch-off transition (b) switch-on transition.

$$
\begin{gathered}
-i_{D 1}+i_{D 2}-i_{D 3}+i_{D 4}+i_{Q 1}-i_{Q 2}=0 \\
i_{D 3}+i_{Q 2}+i_{D 4}+i_{Q 1}=i_{L}
\end{gathered}
$$

The current waveform during switch-off transition is shown in Fig.14(a). The positive spike which exists during this transition is separated into two stages $\left(t_{1} \sim t_{2}\right.$ stage and $t_{2} \sim t_{3}$ stage) to analyze.

Equivalent circuit during $t_{1} \sim t_{2}$ stage is shown in Fig.15(a). For the reason that the right side potential of inductor is higher than the left one, the anode potential of $D_{3}$ and $D_{4}$ is higher than that of $D_{1}$ and $D_{2}$. Therefore the inductor current flows through $T_{1}$ and $T_{2}$ windings rather than $T_{3}$ and $T_{4}$ windings. As $Q_{1}$ switched off, the current flowing through $T_{2}$ starts to fall while the current flowing through $T_{1}$ starts to rise from 0 . Both of them reach steady state when they are $0.5 i_{L}$. At this moment, the current flowing through $Q_{1}$ has already 


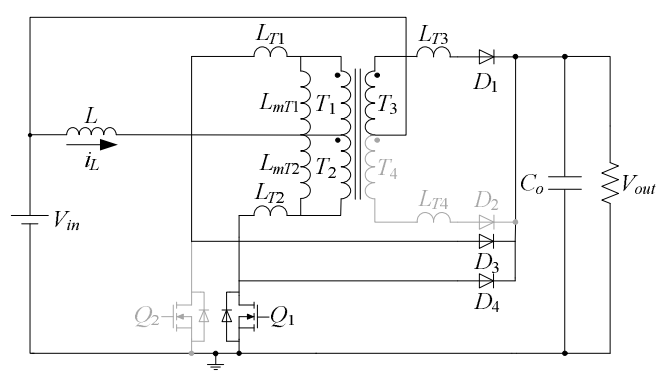

(a)

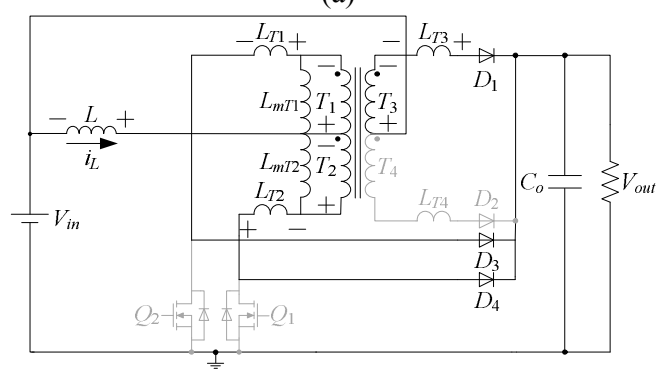

(b)

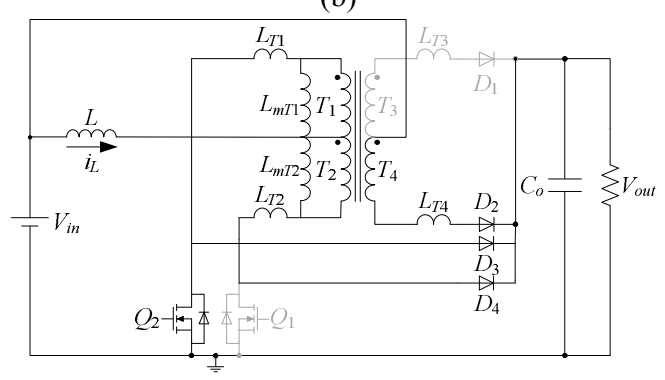

(c)

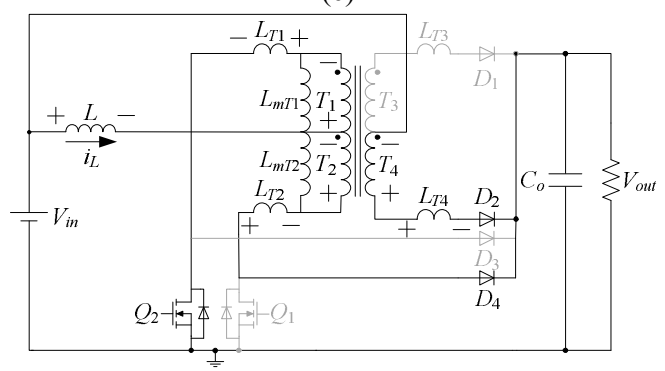

(d)

Fig.15 Equivalent circuit of topology Is 3 during (a) $t_{1} \sim t_{2}$ stage (b) $t_{2} \sim t_{3}$ stage (c) $t_{4} \sim t_{5}$ stage (d) $t_{5} \sim t_{6}$ stage.

fallen to 0 and $i_{T 2}=i_{D 4}$ is satisfied. Compared with the time that $i_{T 1}$ and $i_{T 2}$ reach steady state, the fall time of $Q_{1}$ is much shorter. At $t_{2}, Q_{1}$ has already turned off but $i_{T 1}$ and $i_{T 2}$ haven't reach steady state. Thus $i_{D 4}>i_{D 3}$ is satisfied and output current is the maximum at this moment.

During $t_{2} \sim t_{3}$ stage, $i_{D 3}$ is rising. In contrast, $i_{D 4}$ and $i_{D 1}$ are falling. All of them don't reach steady state until $t_{3}$. At this moment, $D_{1}$ is switched off and both of $i_{\mathrm{D} 3}$ and $i_{\mathrm{D} 4}$ are equal to $0.5 i_{0}$. Equivalent circuit of this stage is shown in Fig. 15(b).

Considering magnetizing inductance and leakage inductance, the winding voltage of transformer is given as

$$
\left\{\begin{array}{c}
v_{1}=-v_{L T 1}-v_{T 1}=v_{\text {out }}-v_{L+} \\
v_{2}=-v_{L T 2}-v_{T 2}=v_{L+}-v_{\text {out }} \\
v_{3}=v_{L T 3}-v_{T 3}=v_{\text {out }}-v_{\text {in }}
\end{array}\right.
$$

Equation (24) is simplified as

$$
-2 L_{T} \frac{d i_{D 1}}{d t}+L_{T} \frac{d i_{D 3}}{d t}-L_{T} \frac{d i_{D 4}}{d t}=2\left(v_{\text {out }}-v_{\text {in }}\right)
$$

During this stage, $i_{Q 1}=i_{Q 2}=i_{D 2}=0$. Equation (26) is simplified from Eq.(22) and Eq.(23)

$$
\frac{d i_{D 1}}{d t}=2 \frac{d i_{D 4}}{d t}=-2 \frac{d i_{D 3}}{d t}
$$

From Eq.(25) and Eq.(26)

$$
6 L_{T} \frac{d i_{D 3}}{d t}=2\left(v_{\text {out }}-v_{\text {in }}\right)
$$

During $t_{1} \sim t_{3}$ stage, the variation of $i_{D 3}$ is $0.5 i_{o}$, so the duration of positive spike is

$$
t_{p-\text { spike }}=t_{3}-t_{1}=\frac{3 L_{T} i_{o}}{2\left(v_{\text {out }}-v_{\text {in }}\right)}
$$

The positive spike is at its maximum at $t_{2}$.

$$
i_{p-\text { spike }}=i_{D 1}+i_{D 3}+i_{D 4}=2 i_{o}-2 \frac{v_{\text {out }}-v_{\text {in }}}{3 L_{T}}\left(t_{2}-t_{1}\right)
$$

In Eq.(29), $t_{2}-t_{1}$ is equal to the fall time of MOSFET $t_{\text {on-off }}$

The current waveform during switch-on transition is shown in Fig.14(b). The negative spike during this transition is separated into two stages $\left(t_{4} \sim t_{5}\right.$ stage and $t_{5} \sim t_{6}$ stage) to analyze.

Equivalent circuit during $t_{4} \sim t_{5}$ stage is shown in Fig.15(c). As $Q_{2}$ is switched on, the current flowing through $T_{1}$ starts to rise from $0.5 i_{L}$ to $i_{L}$ while the current flowing through $T_{2}$ starts to fall from $0.5 i_{L}$ to 0 , the absolute value of $\mathrm{d} i_{\mathrm{T1}} / \mathrm{dt}$ and $\mathrm{d} i_{\mathrm{T} 2} / \mathrm{dt}$ are equal. Since the slope of $i_{Q 2}$ is higher than that of $i_{T 1}$ and $i_{D 3}=i_{T 1}-i_{Q 2}$ is satisfied, the absolute value of $\mathrm{d} i_{\mathrm{D} 3} / \mathrm{dt}$ is higher than that of $\mathrm{d} i_{\mathrm{T} 1} / \mathrm{dt}$. Meanwhile, the slope of $i_{\mathrm{T} 2}$ is equal to that of $i_{D 4}$, so $\left|\mathrm{d} i_{\mathrm{D} 3} / \mathrm{dt}\right|>\left|\mathrm{d} i_{\mathrm{D} 4} / \mathrm{dt}\right|$ is satisfied. That's why $i_{D 3}$ falls faster than $i_{D 4}$. At $t_{5}, i_{D 3}$ has already fallen to 0 and output current is at its minimum.

During $t_{5} \sim t_{6}$ stage, $i_{D 2}$ is rising. In contrast, $i_{D 4}$ is falling. All of them won't reach steady state until $t_{6}$. At this moment, $D_{4}$ is switched off and $i_{D 2}$ is equal to $i_{o}$. Equivalent circuit of this stage is shown in Fig.15(d).

The winding voltage of transformer is

$$
\left\{\begin{array}{c}
v_{1}=-v_{L T 1}-v_{T 1}=0-v_{L-} \\
v_{2}=-v_{L T 2}-v_{T 2}=v_{L-}-v_{\text {out }} \\
v_{4}=v_{L T 4}-v_{T 4}=v_{\text {in }}-v_{\text {out }}
\end{array}\right.
$$

Equation (30) is simplified as

$$
2 L_{T} \frac{d i_{D 2}}{d t}+L_{T} \frac{d i_{Q 2}}{d t}-L_{T} \frac{d i_{D 4}}{d t}=2 v_{\text {in }}-v_{\text {out }}
$$

During this stage, $i_{Q 1}=i_{D 1}=i_{D 3}=0$. Equation (32) is derived from Eq.(22) and Eq.(23) 
TABLE I

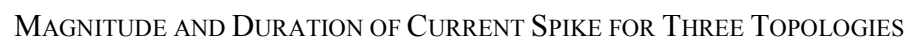

\begin{tabular}{|c|c|c|c|c|}
\hline \multirow{2}{*}{} & \multicolumn{2}{|c|}{ Positive spike } & \multicolumn{2}{c|}{ Negative spike } \\
\cline { 2 - 5 } & Magnitude $i_{\text {mp }}$ & Duration $t_{\text {p-spike }}$ & Magnitude $i_{\text {mn }}$ & Duration $t_{\text {n-spike }}$ \\
\hline Topology IIs1 & 0 & 0 & $i_{o}-\frac{2\left(v_{\text {out }}-v_{\text {in }}\right) t_{\text {on-off }}}{L_{T}}$ & $\frac{L_{T} i_{o}}{2\left(v_{\text {out }}-v_{\text {in }}\right)}$ \\
\hline Topology IIcb2 & $i_{o}-\frac{v_{\text {out }}-v_{\text {in }}}{8 L_{L K}+2 L_{T}} t_{\text {on-off }}$ & $\frac{i_{o}\left(8 L_{L K}+2 L_{T}\right)}{v_{\text {out }}-v_{\text {in }}}$ & 0 & 0 \\
\hline Topology Is3 & $i_{o}-2 \frac{v_{\text {out }}-v_{\text {in }}}{3 L_{T}} t_{\text {on-off }}$ & $\frac{3 L_{T} i_{o}}{2\left(v_{\text {out }}-v_{\text {in }}\right)}$ & $0.5 i_{o}-\frac{v_{\text {in }}-0.5 v_{\text {out }}}{3 L_{T}} t_{\text {off }- \text { on }}$ & $\frac{3 L_{T} i_{o}}{2 v_{\text {in }}-v_{\text {out }}}$ \\
\hline
\end{tabular}

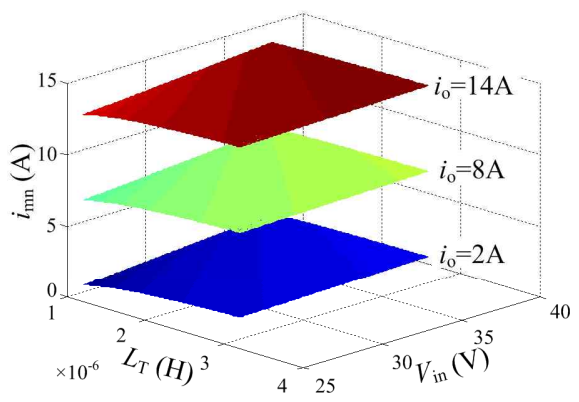

(a)

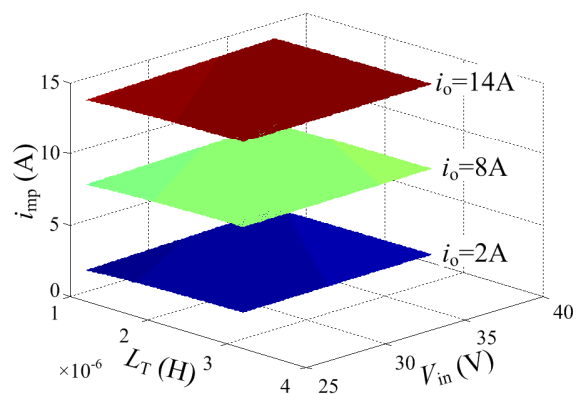

(c)

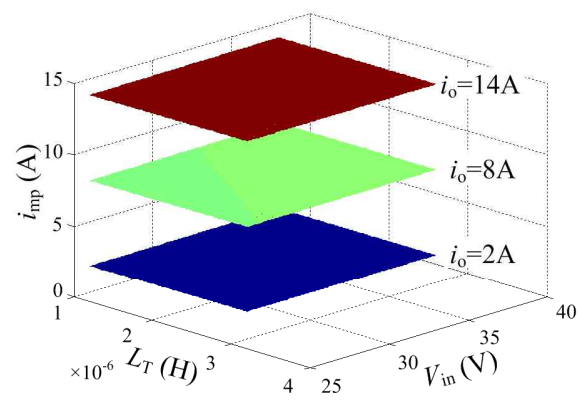

(b)

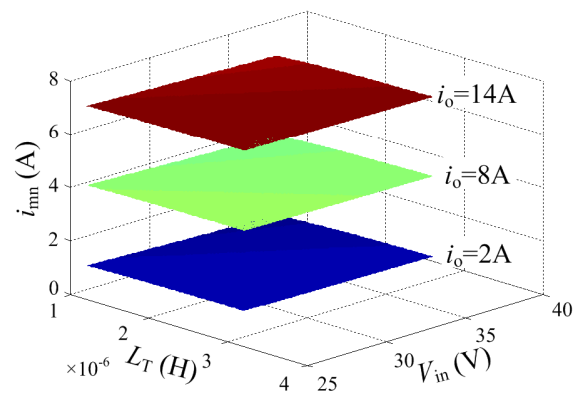

(d)

Fig. 16. Variation of spike magnitude by varying leakage inductance, input voltage and output current without spike for (a) negative spike of topology IIs1 (b) positive spike of topology IIcb2 (c) positive spike of topology Is3 and (d) negative spike of topology Is3.

$$
\frac{d i_{D 2}}{d t}=2 \frac{d i_{Q 2}}{d t}=-2 \frac{d i_{D 4}}{d t}
$$

Substitute Eq.(32) to Eq.(31) yields

$$
-6 L_{T} \frac{d i_{D 4}}{d t}=2 v_{\text {in }}-v_{\text {out }}
$$

The variation of $i_{D 4}$ is $-0.5 i_{o}$ during $t_{4} \sim t_{6}$ stage, so the duration of negative spike is

$$
t_{n-\text { spike }}=t_{6}-t_{4}=\frac{3 L_{T} i_{o}}{2 v_{\text {in }}-v_{\text {out }}}
$$

The negative spike is at its minimum at $t_{5}$.

$$
i_{n-\text { spike }}=i_{D 2}+i_{D 4}=0.5 i_{o}+\frac{v_{\text {in }}-0.5 v_{\text {out }}}{3 L_{T}}\left(t_{5}-t_{4}\right)
$$

In Eq.(35), $t_{5}-t_{4}$ is equal to the rise time of MOSFET $t_{\text {off-on }}$.

\section{FACTORS ON CURRENT SPIKE}

The magnitude of positive spike is

$$
i_{m p}=i_{p-s p i k e}-i_{o}
$$

The magnitude of negative spike is

$$
i_{m n}=i_{o}-i_{n-s p i k e}
$$

Supposing that exciting current and ripple of inductor current can be neglected, magnitude and duration of three topologies are listed in Table I. All of the analysis is based on BDR in a $42 \mathrm{~V}$ PCU system. The specifications of PCU are shown as following.

- Input voltage: $V_{\text {in }}=26 \mathrm{~V} \sim 38 \mathrm{~V}$;

- Output voltage: $V_{\text {out }}=42 \mathrm{~V}$;

- Output current: $i_{\text {out }}=2 \mathrm{~A} \sim 14 \mathrm{~A}$;

- Equivalent switch frequency: $f_{\text {eq }}=20 \mathrm{kHz}$

It is concluded from Table $I$ that the magnitude and duration of spike are relevant to $i_{\mathrm{o}}, v_{\text {in }}$ and $L_{\mathrm{T}}\left(L_{\mathrm{LK}}\right)$. Let it be supposed that $L_{\mathrm{LK}}=0.5 \mathrm{uH}$. Fig. 16 shows the variation of spike magnitude by varying leakage inductance $(1 \mathrm{uH} \sim 3 \mathrm{uH})$, input voltage $(26 \mathrm{~V} \sim 38 \mathrm{~V})$ and output current without spike (2A, 8A, 14A). Fig. 17 shows the variation of spike duration by the 


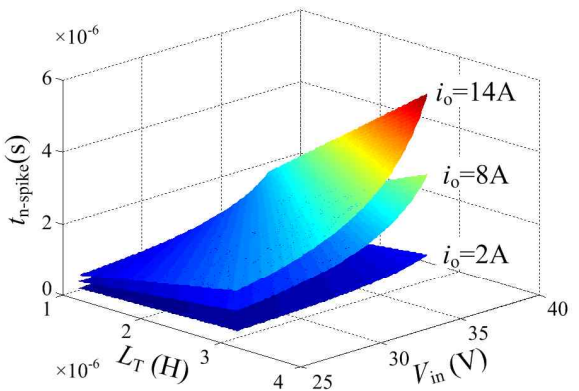

(a)

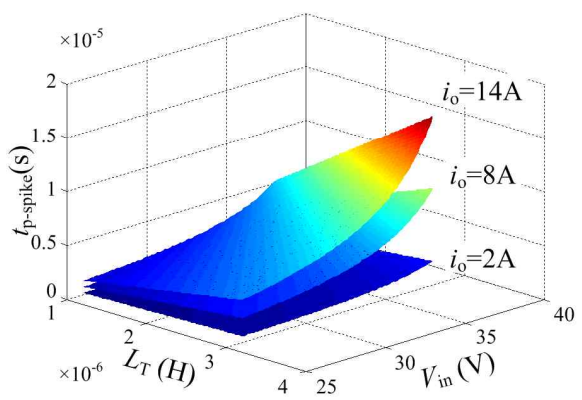

(c)

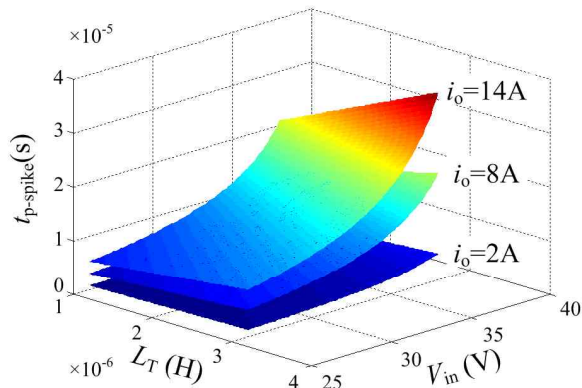

(b)

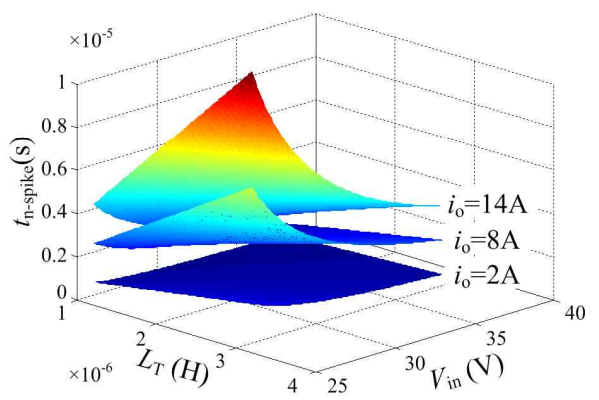

(d)

Fig. 17. Variation of spike duration by varying leakage inductance, input voltage and output current without spike for (a) negative spike of topology IIs1 (b) positive spike of topology IIcb2 (c) positive spike of topology Is3 and (d) negative spike of topology Is3.

same variation range of leakage inductance, input voltage and output current without spike.

We can conclude from Table I that the magnitude and duration of negative spike for topology IIs1 and that of positive spike for topology IIcb2 and Is3 follow the same trend as $i_{\mathrm{o}}, v_{\mathrm{n}}$ and $L_{\mathrm{T}}$ change, which is embodied in Fig.16 and Fig. 17. For topology Is3, the magnitude and duration of negative spike increase as $i_{\mathrm{o}}$ and $L_{\mathrm{T}}$ increase, but fall as $v_{\text {in }}$ increases. Among three topologies, the magnitude of negative spike for topology Is 3 is almost half of the others and the spike duration of topology IIcb2 is the longest.

In a regulated-bus PCU system, $v_{\text {in }}$ and $i_{\mathrm{o}}$ are dependent on time-varying payload power. Thus it is only possible to limit the leakage inductance to decrease the magnitude and duration of spike with time-varying load.

\section{EQuivalent CURRENT SAMPLing METHOD}

The output current of BDR is sampled for current sharing and parameter telemetry. But spike exists in output current, which disturbs the measurement of output current [18]. To overcome this problem, ECSM is adopted.

By ignoring the effect of current spike, the inductor current of topology IIs 1 and Is 3 are equivalent as the output current without spike, which are shown in Fig.6 and Fig.12. As is shown in Fig.9, the sum of primary current and secondary current of coupled inductor is twice of the output current without spike as to topology IIcb2. Hence the equivalent current can be sampled instead of output current. That's why we call it ECSM.

ECSM is suitable for PPCWCCs. For PPCWCCs with single inductor, the current of single inductor is equivalent as the output current without spike [21]. For PPCWCCs generated from push-pull cell II with coupled inductor, the input current and secondary current of coupled inductor can be added to substitute for output current ${ }^{[18]}$. If ECSM is adopted, the sampled current doesn't need to be filtered, which eliminates the sampling time delay and achieves excellent dynamic performance. However ECSM reduces the sampling accuracy and telemetry accuracy because of neglecting the spike.

\section{Problem of Equivalent CuRRent SAMPLing METHOD}

It should be noted that the average value of equivalent current is more or less than that of output current due to the exclusion of spike. In order to achieve excellent current sharing performance, the equivalent current is sampled for inner current loop. For the reason that the reference of each inner loop is the same, the error which is introduced by ECSM will not affect current sharing performance. However, this error affects the telemetry accuracy directly. Parameter telemetry is beneficial to monitor the operation status of BDR in real time. So it is necessary to analyze the error in quality and quantity. According to analysis results, the telemetry value can be compensated to improve the accuracy.

The average value of positive and negative spike is shown as Eq.(38) and (39) respectively. 


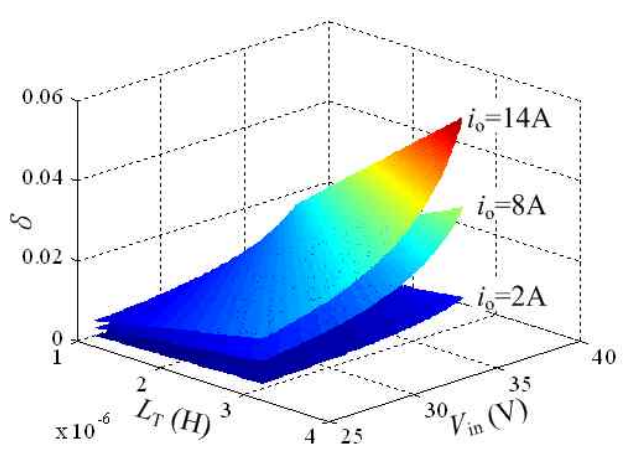

(a)

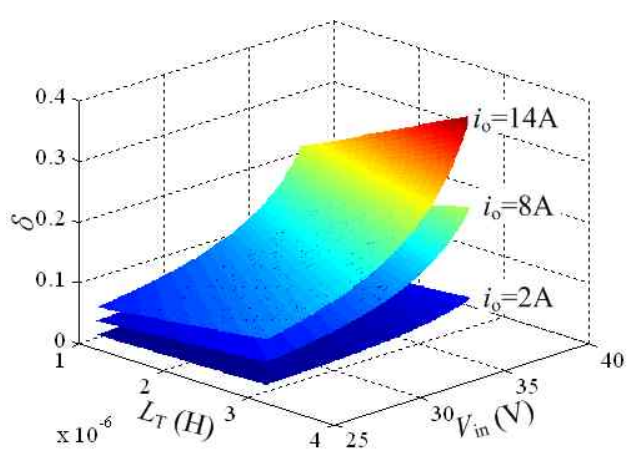

(b)

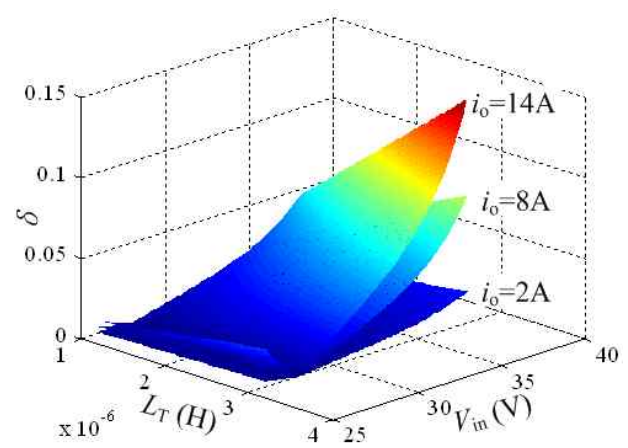

(c)

Fig. 18. Variation of current sampling error rate by varying leakage inductance, input voltage and output current without spike for (a) topology IIs1 (b) topology IIcb2 (c) topology Is3.

$$
\begin{gathered}
S_{p-\text { spike }}=i_{m p} \times t_{p-\text { spike }} \times f_{e q} \times 0.5 \\
S_{n-\text { spike }}=i_{m n} \times t_{n-\text { spike }} \times f_{e q} \times 0.5
\end{gathered}
$$

The ECS error rate is

$$
\delta=\frac{\left|S_{p-\text { spike }}-S_{n-\text { spike }}\right|}{i_{\text {out }}} \times 100 \%
$$

Where $i_{\text {out }}$ is the average value of output current.

Fig. 18 shows the variation of current sampling error rate $\delta$ by varying leakage inductance $(1 \mathrm{uH} \sim 3 \mathrm{uH})$, input voltage $(26 \mathrm{~V} \sim 38 \mathrm{~V})$ and output current without spike (2A, 8A, 14A). It is concluded from Fig. 18 that $\delta$ of topology IIs 1 and IIcb2 increases as $i_{\mathrm{o}}, v_{\text {in }}$ and $L_{\mathrm{T}}$ increase. Similarly, $\delta$ of topology Is 3 increases as $i_{\mathrm{o}}$ and $L_{\mathrm{T}}$ increase, nevertheless, it initially

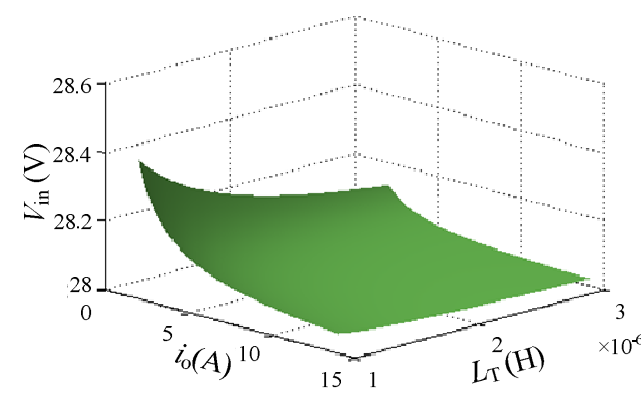

Fig. 19. Relationship among leakage inductance, input voltage and output current without spike when current sampling error rate is equal to 0 for topology Is 3 .

decreases and then increases as $v_{\text {in }}$ increases. This is because that there is a series of $i_{\mathrm{o}}, L_{\mathrm{T}}$ and $v_{\text {in }}$ to satisfy $S_{\mathrm{p} \text {-spike }}=S_{\mathrm{n} \text {-spike }}$ without error. The relationship among $i_{0}, L_{\mathrm{T}}$ and $v_{\text {in }}$ when $\delta=0$ is shown in Fig.19. $\delta=0$ won't be satisfied unless $V_{\text {in }}=28 \mathrm{~V} \sim 28.4 \mathrm{~V}$. Among three topologies, $\delta$ for topology IIs 1 is the lowest and $\delta$ for topology IIcb2 is the highest. Even if $\delta$ for topology Is 3 is equal to 0 under given $i_{\mathrm{o}}, L_{\mathrm{T}}$ and $v_{\mathrm{in}}$, it increases quickly as $i_{\mathrm{o}}, L_{\mathrm{T}}$ and $v_{\text {in }}$ increase.

\section{EXPERIMENTAL RESULTS}

Three experimental prototypes are designed for experimental verification. Component values and operating conditions used for experimental tests are summarized in Table II.

The waveform of equivalent current and output current for the specific $V_{\text {in }}=32 \mathrm{~V}, I_{\text {out }}=7 \mathrm{~A}$ condition, corresponding to the results in Table III, are shown in Fig.20. The error between theoretical analysis and experimental results exists, for the reason that current ripple and exciting current are neglected in theoretical analysis. In total, the experimental result is coincide with the theoretical analysis.

From the experimental waveform in Fig.20, the equivalent current $i_{\text {sample }}$ is approximately equal to the output current without spike for topology IIs 1 and Is 3 or twice of the output current without spike for topology IIcb2. Therefore, $i_{\text {sample }}$ can be easily sampled.

The ECS error rate is obtained from Eq.(41) by measuring output current $i_{\text {out }}$ and equivalent current $i_{\text {sample }}$.

$$
\delta=\frac{\left|i_{\text {out }}-i_{\text {sample }}\right|}{i_{\text {out }}} \times 100 \%
$$

Fig. 21 presents the calculated and measured results for input voltage $v_{\text {in }}$ vs. the ECS error rate. Table I, Eq.(38) and (39) are derived based on the premise that the exciting current and ripple of output current are neglected. In addition, the error is existed in current measuring. That's why the measured results are out of calculated results by $1 \%$ to $2.5 \%$. Overall, the validity of theoretical analysis is proven by measured results. 


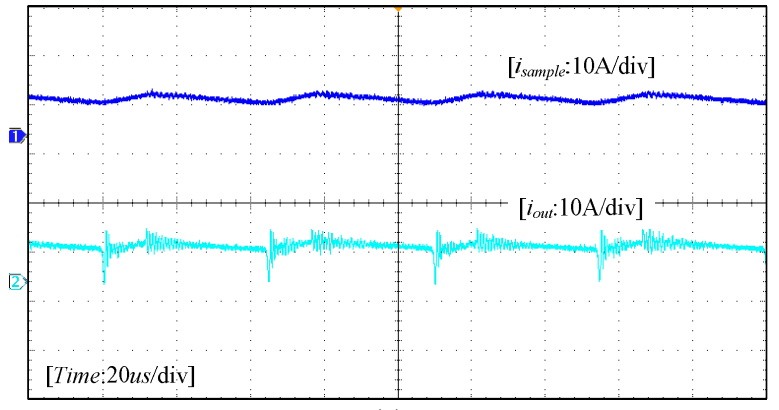

(a)

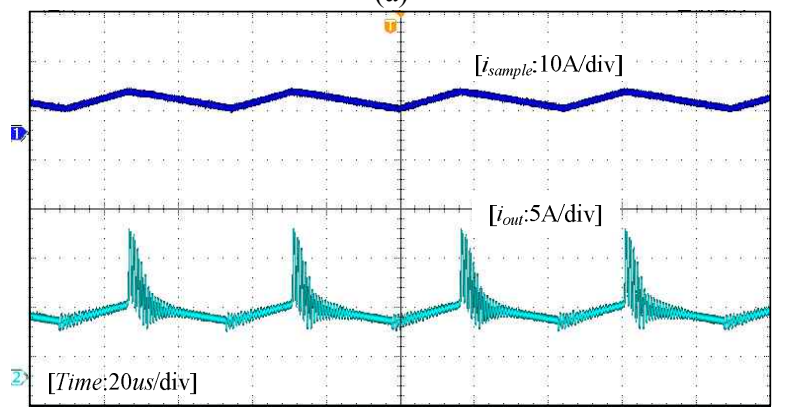

(b)

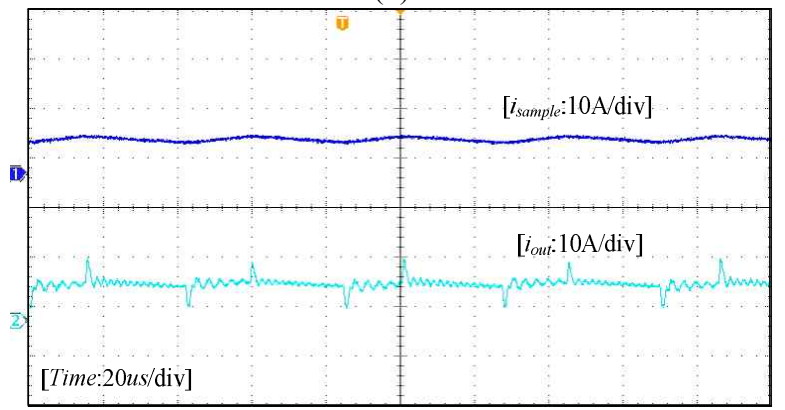

(c)

Fig. 20. Equivalent current and output current for (a) Topology IIs1 (b) Topology IIcb2 (c) Topology Is3.

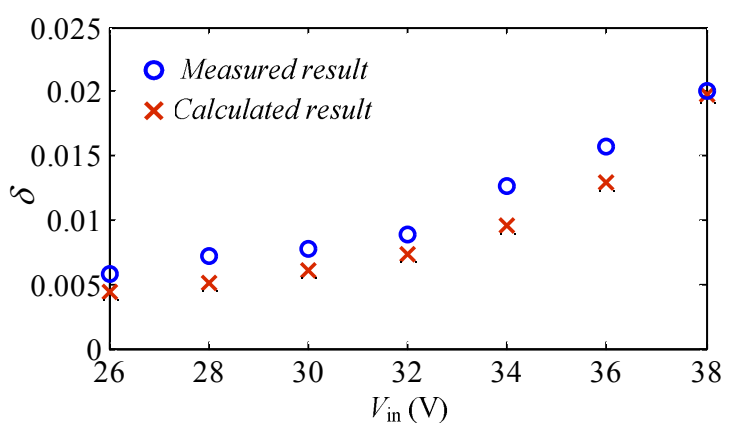

(a)

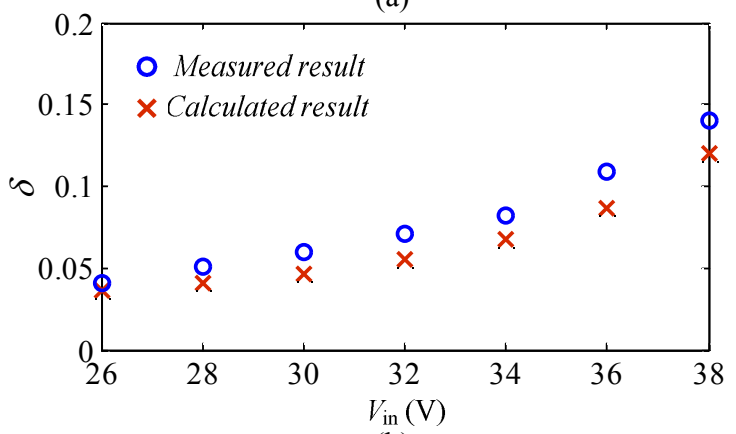

(b)

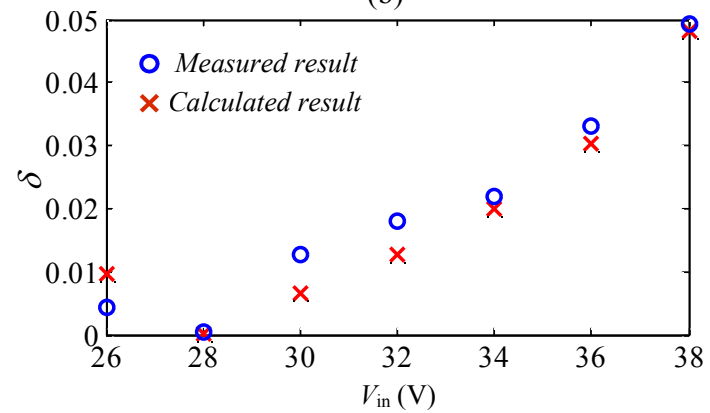

(c)

Fig. 21. Calculated and measured results of current sampling error rate for (a) topology IIs1 (b) topology IIcb2 (c) topology Is 3 when $L_{\mathrm{T}}=2 \mathrm{uH}, I_{\text {out }}=7 \mathrm{~A}$.

TABLE II

COMPONENT VALUES AND OPERATING CONDITIONS FOR THREE TOPOLOGIES

\begin{tabular}{|c|c|c|c|}
\hline & Topology IIs1 & Topology IIcb2 & Topology Is3 \\
\hline MOSFET & \multicolumn{3}{|c|}{ IRF3710 $\left(t_{\mathrm{off}-\mathrm{on}}=58 \mathrm{~ns}, t_{\mathrm{on}-\mathrm{off}}=47 \mathrm{~ns}\right)$} \\
\hline Frequency & $f_{\mathrm{Q} 1}=f_{\mathrm{Q} 2}=11.2 \mathrm{kHz}, f_{\mathrm{Q} 3}=22.4 \mathrm{kHz}$ & $f_{\mathrm{Q} 1}=f_{\mathrm{Q} 2}=11.15 \mathrm{kHz}$ & $f_{\mathrm{Q} 1}=f_{\mathrm{Q} 2}=11.57 \mathrm{kHz}$ \\
\hline Single inductor & $200.15 \mathrm{uH}$ & $/$ & $233.02 \mathrm{uH}$ \\
\hline Coupling inductor & $/$ & $\begin{array}{c}L_{\mathrm{p} 1}=44.02 \mathrm{uH}, L_{\mathrm{s} 1}=172.15 \mathrm{uH}, \\
\mathrm{M}=85.9 \mathrm{uH}\end{array}$ & $/$ \\
\hline \multirow{2}{*}{ Transformer } & & $L_{\mathrm{m}}=458.5 \mathrm{uH}$, & $L_{\mathrm{m}}=389.26 \mathrm{uH}$, \\
& $L_{\mathrm{m}}=465.11 \mathrm{uH}$, & $L_{\mathrm{T} 1}=2.04 \mathrm{uH}, L_{\mathrm{T} 2}=1.98 \mathrm{uH}$ & $L_{\mathrm{T} 1}=2.01 \mathrm{uH}, L_{\mathrm{T} 2}=1.95 \mathrm{uH}$, \\
& & $L_{\mathrm{T} 3}=1.99 \mathrm{uH}, L_{\mathrm{T} 4}=1.98 \mathrm{uH}$ \\
\hline
\end{tabular}

TABLE III

THEORETICAL AND EXPERIMENTAL RESUltS FOR THREE TOPOLOGIES WHEN $V_{\text {IN }}=32 \mathrm{~V}$ AND $I_{\mathrm{O}}=7 \mathrm{~A}$

\begin{tabular}{|c|c|c|c|c|c|c|}
\hline $\begin{array}{c}V_{\text {in }}=32 \mathrm{~V} \\
I_{\mathrm{o}}=7 \mathrm{~A}\end{array}$ & \multicolumn{2}{|c|}{ Topology IIs1 } & \multicolumn{2}{c|}{ Topology IIcb2 } & \multicolumn{2}{c|}{ Topology Is3 } \\
\cline { 2 - 7 } & theoretical & practical & theoretical & practical & theoretical & practical \\
\hline$i_{\text {mp }}(\mathrm{A})$ & $/$ & $/$ & 6.55 & 7.7 & 6.75 & 5.97 \\
\hline$i_{\text {mn }}(\mathrm{A})$ & 6.58 & 6.4 & $/$ & $/$ & 3.3 & 3.98 \\
\hline$t_{\text {p-spike }}(\mathrm{us})$ & $/$ & $/$ & 5.3 & 5.2 & 2.07 & 2.4 \\
\hline$t_{\text {n-spike }}(\mathrm{us})$ & 0.71 & 0.96 & $/$ & $/$ & 1.88 & 1.92 \\
\hline$i_{\text {sample }}(\mathrm{A})$ & 7.052 & 7.05 & 13.23 & 13.02 & 6.91 & 6.87 \\
\hline$i_{\text {out }}(\mathrm{A})$ & 7 & 6.99 & 7 & 6.99 & 7 & 6.99 \\
\hline
\end{tabular}


TABLE IV

The Change Trend of Current Sampling Error Rate vs. $I_{\mathrm{O}}, V_{\mathrm{IN}}$ AND $L_{\mathrm{T}}$ FOR Three Topologies

\begin{tabular}{|c|c|c|c|c|c|c|c|c|}
\hline & & $i_{\text {mp }}$ & $t_{\text {p-spike }}$ & $i_{\text {mn }}$ & $t_{\text {n-spike }}$ & $S_{\text {p-spike }}$ & $S_{\text {n-spike }}$ & $\delta$ \\
\hline \multirow{3}{*}{$\begin{array}{c}\text { Topology } \\
\text { IIs1 }\end{array}$} & $i_{\mathrm{o}} \uparrow$ & $/$ & $/$ & $\uparrow$ & $\uparrow$ & $/$ & $\uparrow$ & $\uparrow$ \\
\cline { 2 - 9 } & $v_{\text {in }} \uparrow$ & $/$ & $/$ & $\uparrow$ & $\uparrow$ & $/$ & $\uparrow$ & $\uparrow$ \\
\cline { 2 - 9 } & $L_{\mathrm{T}} \uparrow$ & $/$ & $/$ & $\uparrow$ & $\uparrow$ & $/$ & $\uparrow$ & $\uparrow$ \\
\hline \multirow{3}{*}{$\begin{array}{c}\text { Topology } \\
\text { IIcb2 }\end{array}$} & $i_{\mathrm{o}} \uparrow$ & $\uparrow$ & $\uparrow$ & $/$ & $/$ & $\uparrow$ & $/$ & $\uparrow$ \\
\cline { 2 - 9 } & $v_{\text {in } \uparrow}$ & $\uparrow$ & $\uparrow$ & $/$ & $/$ & $\uparrow$ & $/$ & $\uparrow$ \\
\cline { 2 - 9 } & $L_{\mathrm{T}} \uparrow$ & $\uparrow$ & $\uparrow$ & $/$ & $/$ & $\uparrow$ & $/$ & $\uparrow$ \\
\hline \multirow{2}{*}{$\begin{array}{c}\text { Topology } \\
\text { Is3 }\end{array}$} & $i_{\mathrm{o}} \uparrow$ & $\uparrow$ & $\uparrow$ & $\uparrow$ & $\uparrow$ & $\uparrow$ & $\uparrow$ & initially $\downarrow$ then $\uparrow$ \\
\cline { 2 - 9 } & $v_{\text {in } \uparrow} \uparrow$ & $\uparrow$ & $\uparrow$ & $\downarrow$ & $\downarrow$ & $\uparrow$ & $\downarrow$ & $\uparrow$ \\
\cline { 2 - 9 } & $L_{\mathrm{T}} \uparrow$ & $\uparrow$ & $\uparrow$ & $\uparrow$ & $\uparrow$ & $\uparrow$ & $\uparrow$ & $\uparrow$ \\
\hline
\end{tabular}

\section{CONCLUSIONS}

PPCWCC which is superior to traditional push pull converter is competitive in aerospace applications. Whereas the problem that spike exists in the low-ripple current is introduced. Considering different current spike characteristics, PPCWCCs which are suitable for BDR are divided into three types, among which the leakage inductance effects are analyzed through topology IIs1, IIcb2 and Is3. ECSM is adopted to overcome the spike disturbance, but introduces current sampling error. This paper analyzes the error in quality and quantity. According to analysis results, the telemetry value can be compensated to improve the accuracy. The conclusions are drawn as follows:

(1) Positive spike exists in topology IIcb2 and Is 3 while negative spike exists in topology IIs1 and Is3.

(2) ECSM which is appropriate for PPCWCCs can be summarized as the following rules: For PPCWCCs with single inductor, the current of single inductor is equivalent as the output current without spike. For PPCWCCs generated from push-pull cell II with coupled inductor, the input current and secondary current of coupled inductor can be added to substitute for output current.

(3) The output current of BDR is sampled for current sharing and parameter telemetry. ECS error rate $\delta$ won't affect current sharing performance. Instead, telemetry accuracy is affected directly.

(4) Table IV presents the trend of ECS error rate $\delta$ vs. $i_{0}$, $v_{\text {in }}$ and $L_{\mathrm{T}}$ for three topologies. $\delta$ of topology IIs1 and IIcb2 increases with the increase of $i_{\mathrm{o}}, L_{\mathrm{T}}$ and $v_{\text {in. }} . \delta$ of topology Is 3 has the same tendency as $i_{\mathrm{o}}$ and $L_{\mathrm{T}}$ increase, nevertheless, it initially decreases and then increases as $v_{\text {in }}$ increases. When $V_{\text {in }}=28 \mathrm{~V} \sim 28.4 \mathrm{~V}$ is accomplished, there is always a series of $i_{\mathrm{o}}$, $L_{\mathrm{T}}$ and $v_{\text {in }}$ to satisfy $S_{\text {p-spike }}=S_{\text {n-spike }}$ without current sampling error.

(5) In view of $\delta$, topology IIcb2 is the most seriously affected by leakage inductor while topology IIs 1 is the most slightly affected. Even if $\delta$ of topology Is 3 is equal to 0 under given $i_{\mathrm{o}}, L_{\mathrm{T}}$ and $v_{\mathrm{in}}$, then it increases quickly as $i_{\mathrm{o}}, L_{\mathrm{T}}$ and $v_{\mathrm{in}}$ increase.
(6) The difference between measured results and calculated results exists for the reason that the calculated results neglect the exciting current and ripple of output current.

(7) PPCWCC for BDR isn't suitable for the application that requires precisely controlled output current.

\section{ACKNOWLEDGMENT}

This work is supported by "Funds for DELTA Science \& Technology educational Development" under Award DREG2011010, "class General Financial Grant from the China Postdoctoral Science Foundation" under Award 2011M500225 and "The Specialized Research Fund for the Doctoral Program of Higher Education of China" under Award 20110009120032.

\section{REFERENCES}

[1] N. Nicolas, L. Didier, A. Peter, etal. "A new modular and flexible power system for LEO missions," in Proceeding of 9th European Space Power Conference, 2011.

[2] P. Morsaniga, G. Gervasio, and G. Cuzzocrea, "Bepicolombo electrical power system," in Proceeding of 9th European Space Power Conference, 2011.

[3] O. Dan, "Lessons learnt in-flight-the STRV micro-satellite power system," in Proceeding of 4th European Space Power Conference, 1995.

[4] M. M. Hansen, "Power conditioning unit for bepicolombo transfer module," in Proceeding of 8th European Space Power Conference, 2008.

[5] H. Jensen and J. Laursen, "Power conditioning unit for Rosetta/Mars express," in Proceeding of 6th European Space Power Conference, pp. 249-256, 2002.

[6] J. P. Castiaux, E. Lecomte, and J. M. Labille, "Modular high power conditioning unit," in Proceeding of 5th European Space Power Conference, pp. 99-104, 1998.

[7] A. Garrigos, J. A. Carrasco, J. M. Blanes, and E. Sanchis-Kilders, "A power conditioning unit for high power GEO satellites based on the sequential switching shunt series regulator," in Proceeding of MELECON, pp. 1186-1189, 2006.

[8] C. S. Clark, A. H. Weinberg, and K. W. Hall, "The design and performance of a power system for the galileo system test bed (GSTB-V2/A)," in Proceeding of 7th European 
Space Power Conference, pp.155-162, 2005.

[9] K. H. Park, C. H. Kim, and H. K. Cho. "Design considerations of a lithium ion battery management system (bms) for the STSAT-3 satellite," Journal of Power Electronics, Vol. 10, No. 2, pp. 210-217, Mar. 2010.

[10] D. H. Jang and S. K. Han. "Low cost high power density photovoltaic power conditioning system with an energy storage system," Journal of Power Electronics, Vol. 12, No. 3, pp. 487-494, May. 2012.

[11] M. S. Ali, H. S. Bae, and S. J. Lee. "Regulated peak power tracking (RPPT) System using parallel converter topologies," Journal of Power Electronics, Vol. 11, No. 6, pp. 870-879, Nov. 2011.

[12] D. O'Sullivan, "Space power electronics-design drivers," ESA Journal, Vol. 18, No. 1, pp.1-23, 1994.

[13] D. Wolfgang and D. Willi, "Generic 100V/high power bus conditioning," in Proceeding of 7th European Space Power Conference, 2005.

[14] L. Soubrier and E. Trehet, "High power PCU for alphabus: PSR100V," in Proceeding of. 9th European Space Power Conference, 2011.

[15] L. Soubrier, P. Besdel, T. Daubresse, and E. Trehet, "High performance BDR for the PCU of alphabus," in Proceeding of 8th European Space Power Conference, 2008.

[16] E. Sanchis-Kilders, E. Maset, and A. H. Weinberg, "ion drive propulsion MPP power conditioning system without battery," in Proceeding of 8th European Space Power Conference, 2008.

[17] E. Maset and A. Ferrers, " $5 \mathrm{~kW}$ Weinberg converter for battery discharging in high-power communications satellites," in Proceeding of IEEE PESC Conference, pp. 69-75, 2005.

[18] A. H. Weinberg and P. Rueda Boldo, "A high power, high frequency, DC to DC converter for space applications," in Proceeding of IEEE PESC Conference, pp. 1140-1147, 1992.

[19] Q. Chen, T. Q. Zheng, and Y. Li, "Derivation and characterization of single-inductor push-pull based topology with continuous current," Proceedings of the CSEE, to be published.

[20] Qian Chen, T. Q. Zheng, and Y. LI, "Continuous current push-pull based topology with coupling inductor used in spacecraft," Transactions of china electrotechnical society, to be published.

[21] J. Aroca, D. Olsson, and J. Maicas, "An efficient BDR topology, able to handle a large battery voltage range," in Proceedings of 5th European Space Power Conference. pp. 33-38, 1999.

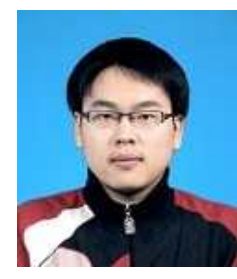

Qian Chen was born in Zhejiang Province, China, in 1987. He received his B.S. degree in Electronic Engineering from Beijing jiaotong University, Beijing, China, in 2009. $\mathrm{He}$ is currently working toward his Ph.D. degree at Beijing jiaotong University. His research interests include power conversion and spacecraft power system.

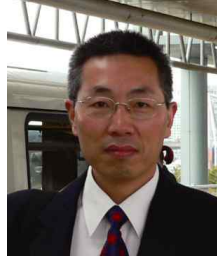

Trillion Q. Zheng (Qionglin Zheng) (M'06-SM'07) was born in Jiangshan, Zhejiang province, China, in 1964. He received the B.S. degree in electrical engineering from Southwest Jiaotong university, Sichuan, China in 1986 and the M.S. and ph.D degrees in electrical engineering from Beijing Jiaotong university, China, in 1992 and 2002, respectively. He is currently a University Distinguished Professor at Beijing Jiaotong University, China. He directs the Center for Electric Traction, founded by Ministry of Education, China. His research interests include power supply and AC dirve of railway traction systems, high performance and low loss for power electronics systems, PV based converters and control, and active power filter and power quality correction. He holds 17 china patents, and has published over 60 journal articles and more than 100 technical papers in conference proceedings. From 2003 to 2011, he served as dean in the school of electrical engineering, at Beijing Jiaotong University. Now he is deputy director of council of Beijing Society for Power Electornics and a member of council of China Electrotechnical Society . He received the Excellent Teacher Award of Beijing Government (1997), Youth Award of Railway Science and Technology of Zhan Tianyou (2005). He was laureates of Youth Elite of Science and Technology of the Railway Ministry of China (1998) and of Zhongda Scholar for power electronics and motor drive area, by Delta Environmental and Educational Foundation (2007).

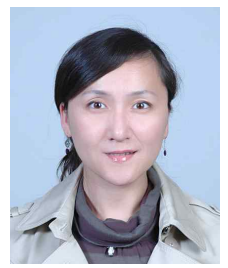

Yan Li was born in Heilongjiang Province, China, in 1977. She received the B.S. and M.S degrees in electrical engineering from Yanshan University, Qinhuangdao, China, in 1999 and 2003, respectively, and the Ph.D. degree in electrical engineering from Nanjing University of Aeronautics and Astronautics, Nanjing, China, in 2009. From 1999 to 2009, she was at Yanshan University. Since 2009, she has been in the School of Electrical Engineering, Beijing Jiaotong University, Beijing, China. Her current research interests include multiple-input $\mathrm{dc} / \mathrm{dc}$ converters, renewable power systems, and PV grid-tied system.

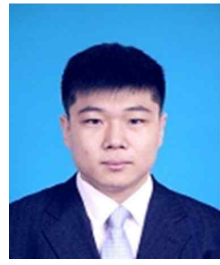

Tiancong Shao was born in Shandong Province. He received the B.S. degree in Electronic Engineering from Beijing jiaotong University, Beijing, China in 2012. He continues Ph.D. degree at Beijing jiaotong University. His current interests include power electronic equipment and high speed train traction drive and control technology. 